\title{
Proposal of a systematic approach to risk assessment \\ and management in space station
}

\author{
Fulvio Enzo RAMUNDO \\ Mechanical and Aerospace Engineering Department \\ University "La Sapienza" \\ Rome - Italy \\ e-mail: fulvio.ramundo@,uniroma1.it
}

\author{
Lorenzo FEDELE \\ Mechanical and Aerospace Engineering Department \\ University "La Sapienza" \\ Rome - Italy \\ e-mail: lorenzo.fedele@uniroma1.it
}

\begin{abstract}
International Space Station (ISS) is the state-of-the-art largest man-made habitable living space. This report is driven to study the complexities and smart ideas to tackle problems in terms of safety and maintenance of such orbiting habitable structure. The problems in space are mostly of different nature than that encountered here on Earth and therefore, different ways and tools have to be developed to solve such issues. Safety is of primary concern in human missions to space: this report tries to investigate safety criticalities, challenges in addressing them and how they could be solved or how they have been solved, from the point of view point of Safety. Both the technical as well as environmental challenges are important to be considered, and are considered. This report also aims to understand how safety can be quantified with a help of FMECA methology, thus, giving an idea to what type of failures are most vulnerable ones and how one can work to eliminate or if not, minimize it. Due to the fact that, the ISS consists of hundreds of thousands of components, only one of the subsystem (propulsion system) has been taken into consideration during the analysis. However, most of the major, systems, sub-systems, and their components have been enlisted to better understand the important aspects of the space station.
\end{abstract}

Keywords: Safety, International Spcace Station.

\section{INTRODUCTION}

International Space Station (ISS - Fig. 1) is a habitable artificial satellite in Low Earth Orbit (LEO), with multiple segments assembled in the space. The ISS serves as a microgravity and space environment research laboratory, and mainly consists of the following main components: pressurized habitation module, structural trusses, solar arrays, radiators, docking ports, experimental bays, robotic arms.

This research laboratory conducts experiments in physics, astronomy, meteorology, biology, human biology, life sciences, space medicine, testing spaecraft systems and equipment for missions to the Moon and Mars [1].The ISS maintains an orbit with an altitude of between 330 and 435 $\mathrm{km}$, and circles the Earh in roughtly 92 minutes and completes 15,5 orbits per day [2]. It is a joint venture among five space agencies namely the following: NASA (USA), JAXA (Japan), ESA (Europe), CSA (Canada).

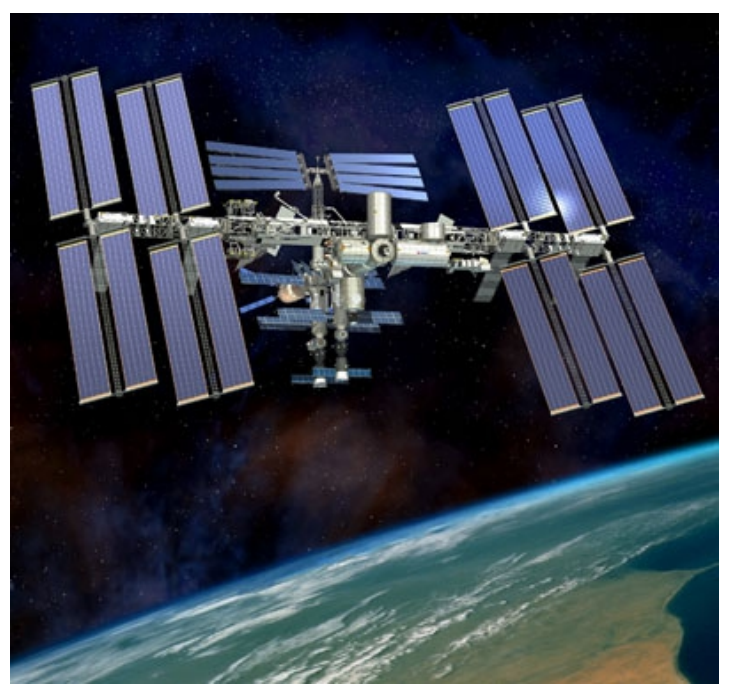

Figure 1: a photograph of ISS [source: ESA]

International Space Station has encountered several maintenance issues, unexpected probems and failures, some of which are critcal ones. The safety of the astonauts onboard spacecraft is of major priority, thus for which lot of safety and maintenance procedures are followed. However, despite all the scheduled safety procedures, accidents or failures are inevitable. Some of the major incidents [3, 4, 5, 6] are reported in table n.1 :

Table 1: Failure / Accidents in ISS

\begin{tabular}{|c|l|}
\hline Year & \multicolumn{1}{|c|}{ Failure / Accident } \\
\hline 2003 & Waste accumulation after the Columbia disaster \\
\hline 2004 & Air leak and Elektron oxygen generator failure \\
\hline 2005 & Elektron oxygen generator fails \\
\hline 2006 & Venting of gas \\
\hline 2007 & Computer failure \\
\hline
\end{tabular}




\begin{tabular}{|c|l|}
\hline 2007 & Torn solar panel \\
\hline 2007 & Damaged starboard Solar Alpha Rotary Joint \\
\hline 2009 & Excessive vibration during reboost \\
\hline 2009 & $\begin{array}{l}\text { Potential ammonia leak from S1 radiator due to } \\
\text { damaged panel }\end{array}$ \\
\hline 2010 & Failure in cooling loop A (starboard side) \\
\hline 2011 & Near collision with space debris \\
\hline 2012 & $\begin{array}{l}\text { Failure of primary Carbon Dioxide Removal } \\
\text { Assembly (CDRA) }\end{array}$ \\
\hline 2018 & Leak in Soyuz Orbital Module \\
\hline
\end{tabular}

\section{THE SPACE ENVIRONMENT}

The safety risks arise predominantly from various elements of the ambient space environment encountered during the operational evolution of a mission. Therefore, it is very important to consider the space environment when dealing with the safety of space systems. Space environments, critical in terms of safety and risk for space systems, can be be classified as follow: atmosphere, orbital debris and metheroids, microgravity, acoustics, radiation, natural and induced thermal environments.

\section{Atmosphere}

An atmosphere is the gaseous envelope surrounding a planetory body such as the Earth. It is very important factor to be considered while planning a missions in LEO and for all launches of rockets. For example the atomospheric density which influences on aerodynamic drag and the corresponding torques, or the temperature and composition which affect the degradation of materials. Referring to atmospheric model CIRA 72, figure 2.1 shows mean values for temperature, density and composition as function of altitude.
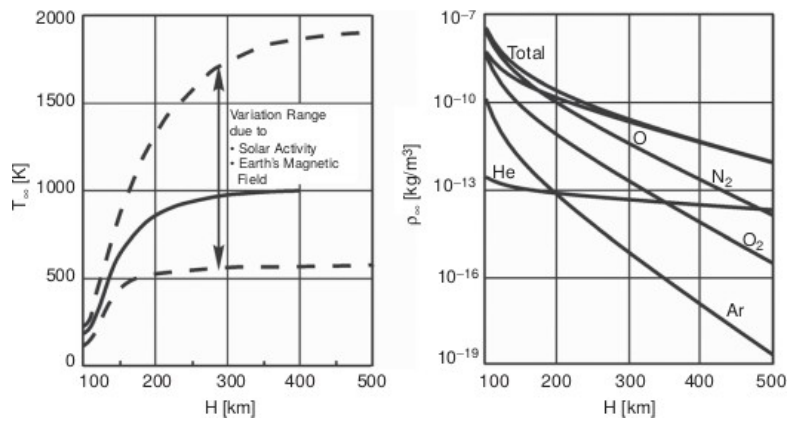

Figure 2.1: Left: Temperature and Right: Composition with average density profile with increasing altitude [7].

The influence of the atomosphere on space vehicles are as follows:

- at relative velocities of $8 \mathrm{~km} / \mathrm{s}$, considerable impulse and energy exchange takes place between ambient flow and spacecraft. The aerodynamic forces induce torques that can change the attitude of the space vehicle. Both influences must be balanced by active attitude and orbit control systems;

- gas particles, atomic oxygen in particular, that impact the surface of a space vehicle can have meachanically or chemically erosive effects;

- sometimes, gas particles in the atmosphere collide with the gases emitted by the vehicle. This can result in contamination of the vehicle surface, for example, deposition of materials on optical glasses;

- in low orbits, aerodynamic heating plays an important role.: aerodynamic heating decreases with increasing altitudes.

\section{Orbital Debris and Meteoroids}

Orbital debris are pieces from spacecraft, that have been launched in space and now circle around the Earth: often contain fuel or high-pressure fluids.

They are very fast moving objects and can travel at speeds 6.9 to $8 \mathrm{~km} / \mathrm{sec}$, thus it can easily damage spacecraft or satellite. The rising population of space debris increase the potential danger to all space vehicles, but especially to the International Space Station, or spacecraft with humans aboard. Figure 2.2 shows monthly number of objects in Earth's orbit officially cataloged by the U.S. Space Surveillance Network [8].

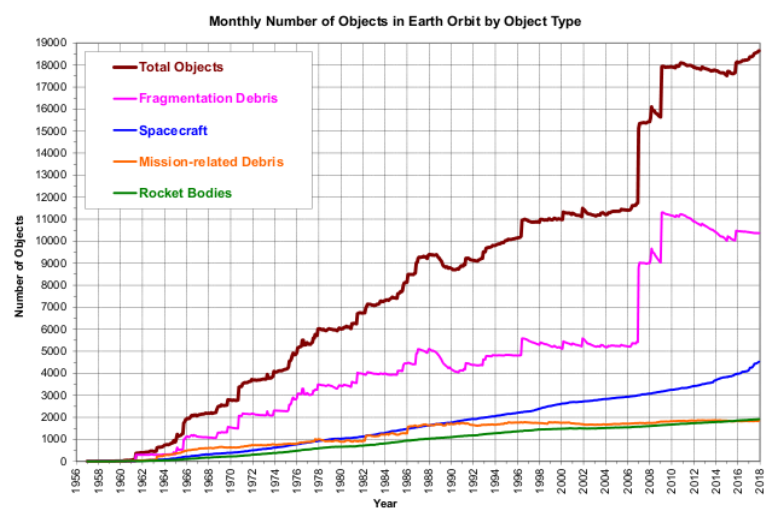

Figure 2.2 Monthly number of objects in Earth's orbit. [8]

\section{Orbital Debris Mitigation}

To reduce the orbital debris threat to future space operations, NASA has established policy to guide programs in minimizing additional Meteoroids and Orbital Debris environment by reducing the number of objects releases in space and lowering the possibility of accidental breakup. NASA Management Instruction 1700.8 defines the "Policy for Limiting Orbital Debris Generation" and calls for a formal assessment of programs relative to orbital debris generation potential.

NASA Safety Standard 1740.14 "Guidelines and Assessment Procedures for Limiting Orbital Debris"", provides details on how to perform the assessment required by NASA policy: assessments are to be performed at least twice during a program cycle, prior to the Preliminary Design 
Review (PDR) and prior to the Critical Design Review (CDR) [9].

\section{Meteoroids}

In contrast to orbital debris, most of the meteoroid mass is composed of small particles with diameters of about 200 $[\mu \mathrm{m}]$ and with corresponding masses of about $1,5 \times 10^{\wedge-5}[\mathrm{~g}]$. The risk of meteoroids on space systems is generally low as compared to that of space debris, despite the much higher meteoroid impact velocities of upto $72[\mathrm{~km} / \mathrm{s}]$.

NASA has addressed the threat of meteroids and orbital debris to orbiting spacecraft by establishing a "Meteoroid and Orbital Debris Technology Program (M/OD TP)", managed by the Systems Analysis and Integration Laboratory at the Marshall Space Flight Center.

\section{Microgravity}

Microgravity is the condition of apparent weightlessness provided in a free fall. The ISS based micorgravity accleration measurement ssytem consists of the following instruments:

- Low frequency triaxial acclererometer;

- Miniature electrostatic accelerometer;

- High frequency acclerometer;

- High resolution accelerometer;

- and associated computer, power, and signal processing subsystems.

The microgravity accleration measurement system records low frequecy acclerations which are related to aerodynamic drag, gravity gradient and rotational effects, venting of gas or water and mechanical movement [7].

\section{Micorgravity effect on biological processes and astronaut} Health

Weightlessness is demostrated to have some harmful effects on human health and performance which can both be temporary and long-term health issues. Some of the majoy physical and psychological effects are discussed below:

- $\quad$ Space Adaption Syndrome;

- Skeletal Declacification

- Muscle Atrophy.

In order to reduce this effects, astronauts carry out regular exercises particularly strength training exercises, combined with an adequate diet onboard ISS.

Some other important physiological effects include the following:

- Weakening of the cardiovascular system;

- Decreased production of red blood cells (RBCs);

- Balance disorders;

- Decreased effectiveness of the immune system.

These effects are reversible on return to Earth. Many of the conditions caused by exposure to weightlessness are smilar to those resulting from aging [7].

\section{Acoustics}

The acoustic environment in space operation is important to maintain at manageable levels so that the crew can remain safe, functional, effective and resonably comfortable. High aacoustic levels can cause temporary or permanent hearing loss or cause other physical symptoms, such as auditory pain, headaches, discomfort, strain in the vocal cords inability to sleep, errors in judgment, distractions, irritability, inability to concentrate or fatigue etc.

Fans are the dominant noise sources within the Space Shuttle flight deck and ISS, thus these days mufflers are added to offset the fan noise. There exists three basic sound paths in space systems [10]: Air borne, Structure borne, Enclosure radiated.

\section{Radiation}

The predominant types of particle radiation in space arise from distinct sources and can be classified as follows:

- Solar Particle Radiation;

- Galactic Cosmic Radiation;

- Trapped Radiation Belts.

Astronaut living on the International Space Station is exposed to over 80 times the amount on the Earth: reduction of radiation risk in ISS orbit can be relatively easy, while astronauts to and from the Moon or Mars must pass through the Van Allen belts and be exposed for brief periods to high levels of radiation [7].

\section{Space radiation protection}

In the context of the radiation protection principle of "as low as resonably achievable" (ALARA), the term safety means that acceptable risks are not exceeded during the lifetime of crew members, where acceptable risks include limits on post-mission and multimission consequences. The most important types of radiation for biological consideration are the trapped protons in the inner zone, the trapped electrons in both the inner and the outer zones, solar particle events and especially the galactic cosmic radiation. Safety concerns for long-term space explorations include the following:

- Carcinogenesis;

- Degenerative tissue effects such as cataracts;

- Heart disease;

- Acute Radiation Syndrome (ARS);

- Damage to control nervous system [28].

Some effective mitigation against solar particle events are [28]:

- a spacecraft devised using high-performance structural material, having effective radiation shielding properties;

- adequate mission planning for timing and location;

- seeking a shelter and using personal localized shielding in a timely manner.

\section{Space Safety and ISS Safety Task Force}

Space missions are considered to be very risky, mostly due to extreme nature of the space environment and existing technological limitations in additional to design and manufacturing decisions. Accidents happen because of failures, malfunctions, operational errors, or combination of these. The main causes for failures and malfunctions are design and manufacturing errors [11]. Design errors are generally of three types:

- Wrongly assumed or underestimated environmental conditions, such as limit loads or worst cases; 
- Deficient control or intrinsic hazardous characteristics, such as flammable materials or stored energy;

- Incorrect or inaccurate detailed design.

Prevention of human error is an integral part of a good design. In the past, human operational errors were controlled mainly through instruction and training.

The following are basic safety principles and methods common to several industries, which are used to minimize the possibility of accidents and reduce the consequences of accident:

1) Hazard elimination and limitation;

2) Barriers and interlocks;

3) Fail-safe design [12];

4) Failure risk minimization;

5) Monitoring, recovery and escape.

International Space Station Independent Safety Task Force

Following the loss of the Space Shuttle Columbia (on February 1, 2003), in 2006 the International Space Station Safety Task Force (IISTF) was established to review a broad range of Station vulnerabilities and consequences, furthemore in 2009 an ISS Emergency Operations team was formed to improve emergency response on ISS.

The IISTF's approach to the assigned tasks was two dimensional. First, it identified vulnerabilities (hazards) that could cause ISS destruction, compromise crew health or necessitate the premature abandonment of the ISS. Second, the it reviewed the ISS Program's management functions, consisting of plans, procedures, governing processes, and management processes, that should provide advanced indications and warnings which will avoid events, that might lead to destruction of the ISS, loss of the crew, or abandonment of the Station as well as avoid crew health problems.

\section{Threats to And Vulnerabilities of the INTERNATIONAL SPACE STATION}

The threats and vulnerabilities identified by the IISTF and the steps that ISS Program takes to mitigate them are widely described in [13]. The primary factors identified as potential threats, to the ISS crew and the Station, are:

- Micro-Meteoroid and Orbital Debris damage (MMOD);

- collision with visiting vehicles or Remote Manipulator System (RMS);

- on-board fire;

- toxic spills in the crew-habitable volume;

- acoustics;

- plasma shock and induced current hazard.

Referring to these factors, this research explores possible failure/accident scenarios that could occur, through an FMECA analysis.

\section{SYSTEM, SUBSYSTEMS AND THEIR FAILURE MODES}

The ISS consists of multiple systems and subsystems [3] for its operations, most of the systems are continuously on operation, some are partially operational while the rest are for redundancy purpose. ISS flight systems make higher the core functional infrastructure of the on-orbit ISS. The sections and subsections in this chapter are intended to give an overview to such systems, subsystems, components and their subcomponents. It is then followed by the identification of failure modes, their causes and effects and carry out quantitative analysis for the risk assessment of the system. ISS can be divided in Flight System and Integrated Truss Structure (ITS);

\section{Failure Mode, Effects and Criticality Analysis on ISS}

FMECA was one of the first systematic techniques for failure analysis and was developed by the U.S. Military. The first guideline was Military Procedure MIL-P-1629 "Procedures for performing a failure mode, effects and criticality analysis" in 1949. It ensures all conceivable failure modes and their effects on operational success of the system. It also lists potential failures and identify the severity of their effects. The criticality ranking for the FMECA analysis is the following:

Table 5.1: Criticality ranking definition for FMECA.

\begin{tabular}{|c|l|}
\hline $\begin{array}{c}\text { Criticality } \\
\text { Ranking }\end{array}$ & \multicolumn{1}{|c|}{ Definitions } \\
\hline 1 & Minimum or no impact (best) \\
\hline 2 & $\begin{array}{l}\text { Minor impact on process, process shut-down } \\
\text { not required }\end{array}$ \\
\hline 3 & $\begin{array}{l}\text { Major impact on process, significant hazard, } \\
\text { orderly process shut-down required }\end{array}$ \\
\hline 4 & $\begin{array}{l}\text { Immediate hazard, emergency shut-down } \\
\text { required (worst) }\end{array}$ \\
\hline
\end{tabular}

Similarly, the likelihood of occurrence ranking for the FMECA analysis is the following:

Table 5.2: Likelihood ranking definition for FMECA.

\begin{tabular}{|c|c|l|}
\hline $\begin{array}{c}\text { Likelihood } \\
\text { Ranking }\end{array}$ & Category & \multicolumn{1}{|c|}{ Definitions } \\
\hline 1 & Improbable & $\begin{array}{l}\text { Extremely remote possibility. } \\
\text { Strong controls are in place. }\end{array}$ \\
\hline 2 & Remote & $\begin{array}{l}\text { Could happen, controls have } \\
\text { minor limitations. }\end{array}$ \\
\hline 3 & Infrequent & $\begin{array}{l}\text { Could happen, controls have } \\
\text { significant limitations. }\end{array}$ \\
\hline 4 & Probable & Expected to happen. \\
\hline
\end{tabular}


Some major failure modes, their causes, effect, criticality and likelihood along with the functions of the major components and sub-components of propulsion system are tabulated below [3].

Table 5.3: Components of Propellant Storage Tanks

\begin{tabular}{|c|l|l|}
\hline \multicolumn{3}{|c|}{ PROPELLANT STORAGE TANKS } \\
\hline I.D. & \multicolumn{1}{|c|}{ COMPONENT } & \multicolumn{1}{c|}{ FUNCTION } \\
\hline P1.1 & $\begin{array}{l}\text { Fuel and oxidizer } \\
\text { valve }\end{array}$ & Control mass flow rate \\
\hline P1.n & $\ldots$ & $\ldots$ \\
\hline P1.7 & Slosh bafflers & $\begin{array}{l}\text { Damp propellant } \\
\text { sloshing }\end{array}$ \\
\hline
\end{tabular}

Table 5.3.1: FMECA for Propellant Storage Tanks

\begin{tabular}{|c|l|l|l|}
\hline \multicolumn{4}{|c|}{ PROPELLANT STORAGE TANKS } \\
\hline I.D. & Failure mode & Failure cause & Effect of failure \\
\hline P1.1A & $\begin{array}{l}\text { Fail open / } \\
\text { close }\end{array}$ & Corrosion & $\begin{array}{l}\text { Engine shut } \\
\text { down }\end{array}$ \\
\hline P1.nx & $\ldots$ & $\ldots$ & $\ldots$ \\
\hline P1.7C & Creep & Fluid stress & $\begin{array}{l}\text { Damage bafflers } \\
\text { leading to } \\
\text { loss of control }\end{array}$ \\
\hline
\end{tabular}

It is possible to process FMECA analyzes for any other system and sub-system, and this has been done for the following components of the ISS: Propellant Feed System, Thrust chamber, Electrical and supporting system, Tank pressurization system. Some more significant examples are shown below:

Table 5.4: Components of Propellant Feed System

\begin{tabular}{|c|l|l|}
\hline \multicolumn{3}{|c|}{ PROPELLANT FEED SYSTEM } \\
\hline I.D. & \multicolumn{1}{|c|}{ COMPONENT } & \multicolumn{1}{c|}{ FUNCTION } \\
\hline P2.1 & $\begin{array}{l}\text { Fuel and oxidizer } \\
\text { pump }\end{array}$ & $\begin{array}{l}\text { Pump propellant from } \\
\text { tank }\end{array}$ \\
\hline P2.n & $\ldots$ & $\ldots$ \\
\hline P2.5 & Gas generator & Run pumps \\
\hline P2.m & $\ldots$ & $\ldots$ \\
\hline P2.11 & Pressure switch & $\begin{array}{l}\text { Prevent over } \\
\text { pressurization }\end{array}$ \\
\hline
\end{tabular}

Table 5.4.1: FMECA for Propellant Feed System

\begin{tabular}{|c|l|l|l|}
\hline \multicolumn{4}{|c|}{ PROPELLANT FEED SYSTEM } \\
\hline I.D. & \multicolumn{1}{|c|}{$\begin{array}{c}\text { Failure } \\
\text { mode }\end{array}$} & $\begin{array}{c}\text { Failure } \\
\text { cause }\end{array}$ & Effect of failure \\
\hline P2.1A & $\begin{array}{l}\text { Damage } \\
\text { rotor blades }\end{array}$ & $\begin{array}{l}\text { Strees - } \\
\text { Fatigue }\end{array}$ & $\begin{array}{l}\text { Pump } \\
\text { breakdown }\end{array}$ \\
\hline P2.nx & $\ldots$ & $\ldots$ & $\ldots$ \\
\hline P2.5A & F/O Leakage & $\begin{array}{l}\text { Piping } \\
\text { damage }\end{array}$ & Engine failure \\
\hline P2.5B & Fire & Leakage & Engine damage \\
\hline P2.mx & $\ldots$ & $\ldots$ & $\ldots$ \\
\hline P2.11A & Fail on/off & $\begin{array}{l}\text { P sensor } \\
\text { breakdown/ } \\
\text { corrosion }\end{array}$ & $\begin{array}{l}\text { Over } \\
\text { pressurization }\end{array}$ \\
\hline
\end{tabular}

Table 5.5: Components of Electrical and supporting system

\begin{tabular}{|c|l|l|}
\hline \multicolumn{2}{|c|}{ ELECTRICAL AND SUPPORTING SYSTEM } \\
\hline I.D. & \multicolumn{1}{|c|}{ COMPONENT } & \multicolumn{1}{c|}{ FUNCTION } \\
\hline P4.1 & Gimbal mounting & $\begin{array}{l}\text { Workbench for gimbal } \\
\text { actuators }\end{array}$ \\
\hline P4.n & $\ldots$ & $\ldots$ \\
\hline P4.5 & $\begin{array}{l}\text { Electricla lines \& } \\
\text { sesors }\end{array}$ & Supply power \& signal \\
\hline
\end{tabular}

Table 5.5.1: FMECA for Electrical and supporting system

\begin{tabular}{|c|l|l|l|}
\hline \multicolumn{4}{|c|}{ ELECTRICAL AND SUPPORTING SYSTEM } \\
\hline I.D. & \multicolumn{1}{|c|}{$\begin{array}{c}\text { Failure } \\
\text { mode }\end{array}$} & $\begin{array}{c}\text { Failure } \\
\text { cause }\end{array}$ & Effect of failure \\
\hline P4.1A & $\begin{array}{l}\text { Buckling/ben } \\
\text { ding }\end{array}$ & $\begin{array}{l}\text { Exceeding } \\
\text { force }\end{array}$ & Loss of control \\
\hline P4.nx & $\ldots$ & $\ldots$ & $\ldots$ \\
\hline P4.5A & Fail to sense & $\begin{array}{l}\text { Electrical } \\
\text { failure }\end{array}$ & Loss of control \\
\hline P4.5B & Short circuit & Power outage & Fire hazard \\
\hline
\end{tabular}

Based on the classification of the probability and the criticality, it is possible to assign values to each subsystem, in order to construct a risk matrix (Figures: 5.1, 5.2, 5.3, 5.4): the I.D. allows to identify the subsystem, as described in the FMECA tabulation. 


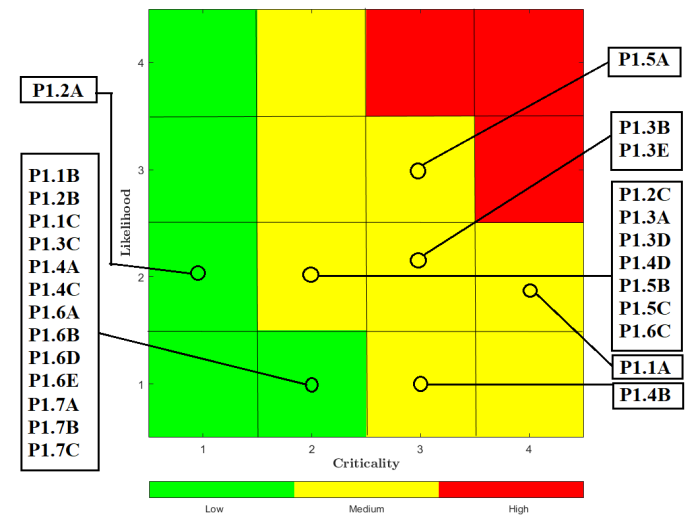

Figure 5.1: Risk matrix for the Propellant Storage Tank.

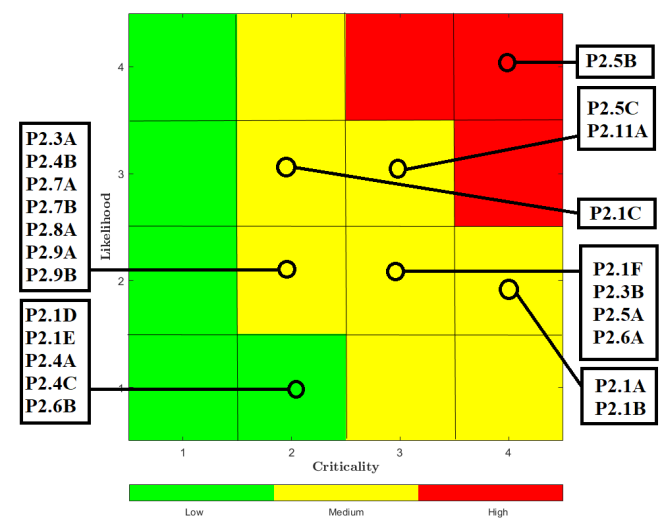

Figure 5.2: Risk matrix for the Propellant Feed System.

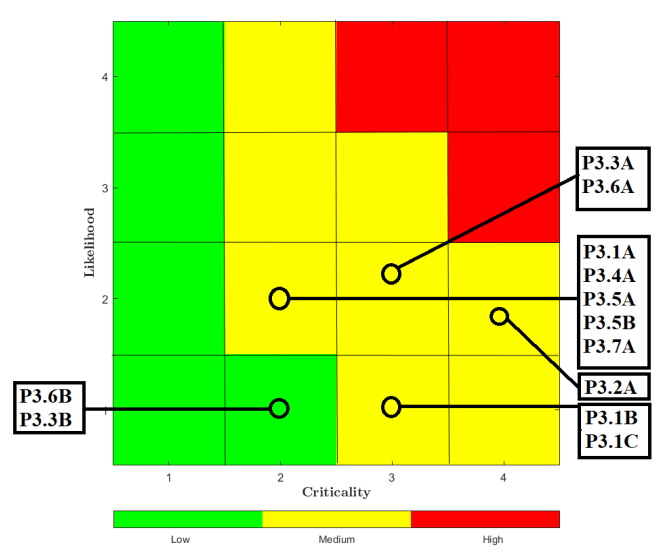

Figure 5.3: Risk matrix for Trust chamber

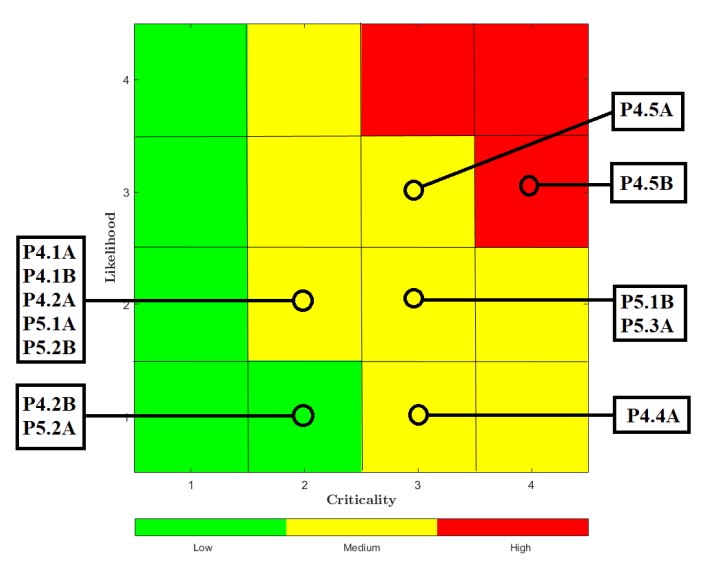

Figure 5.4: Risk matrix for Electrical and supporting system and Propellant Storage Tank

The risk matrixes illustrate that most of the issues are within the mitigating range and therefore can be handled with some efforts. The most critical ones involve P2.5B and P4.5B, which are fire and short-circuit failure modes. Since, the system is equipped with both fuel and oxidizer which are stored in high pressure vessels, the ones which initiate an unintentional ignition like that by fire and short-circuit are critically hazardous, as far as the propulsion system is concerned. The ignition sources to be addressed are hot surfaces, sparks from mechanical impacts, electrical arcs and sparks, and electrostatic arcs. Some of the preventive measures for such incidents are:

- Selection of Materials: Materials which are inherently nonflammable or self extinguishing in the space environment can be of the primary preference when selecting the materials for the propulsion system. However, due to mechanical, and physical limitations such materials are very difficult to use thus, the best way is the use flammable materials as in small quantities as possible.

- Isolation of the fire prone systems: The electrical and power storage systems, which contains internal electronics are very likely to fire (even due to short-circuit or overheating), thus effective isolation or sealing with no vent openings or effective cooling channel with sufficient heat, fire or smoke sensors are to be installed. Inert gases such as nitrogen can also be used to prevent fire spreading.

- Sealing electrical equipments: The electrical ignition sources such as relays, switches, motors and other similar ignition sources should be properly tested (according to MILSTD-810F) and should be properly sealed;

- Sensors installation: Various detectors like smoke detectors, thermal detectors, gaseous detectors, species sensors, radiation sensors, etc. which can detect and alarm the potential fire and/or leakage should be installed in appropriate positions and their sensitivity should be at its maximum [15]. 
In case of emergency i.e. when a small fire or smoke detected, the effectiveness and automation to fire extinguish system should increased, the system should respond it immediately.

- Readily availability of suppressant: The gaseous carbon dioxide, which is considered to be the primary fire suppressant because of its effectiveness on the range of fires, compatibility with spacecraft systems and ability to remove it from the cabin atmosphere by on-board systems, should be easily available for the crew in case of an emergency.

- Use of aqueous foams: Foam suppression agents act by forming a stable, homogeneous blanket over the combustible solid or liquid that cools the surface while excluding air, sealing liquids, and preventing flammable vapours from being emitted. Water can also be an another fire suppression agent whose advantage in spacecraft are effective on many types of fires, zero toxicity, the ability to be removed from the atmosphere through the humidity control system. The disadvantages of its use include electrical conductivity, reactivity with certain metals [15].

- Use of hardline oxygen: Use of hardline oxygen requires the crew to wear a mask that plugs into the ISS oxygen system to provide breathing oxygen to the crewmembers during a fire scenario.Due to the design of the mask, significant oxygen leakage from the mask is expected in this scenario and will rapidly increase the oxygen concentrations throughout the affected modules. Elevated oxygen concentrations around their face in the presence of an active fire is not a safe practice. To address this risk, fire cartridges have been developed to be used with respirators during fire response.

- De-pressurization: The process of de-pressurization (remove all the oxygen) is considered as one of the ultimate choice of option for fire safety due to its challenges in repressurization. It can also be an effective post-fire method to remove combustion products from the atmosphere.

\section{Maintenance of ISS}

Maintenance is very vital part of operation management and plays an important role to insure safety of people in orbit. Unlike regular maintenance strategies on Earth, maintenance in orbit is very complex and unique in many aspects. The crew members on board the ISS are responsible not only for operating the station, but also for regularly maintenance it. There are two types of on-orbit maintenance:

- Preventive maintenance:It involves inspection, replacement and cleaning tasks that the astronauts train before their mission.

- Corrective maintenance:It requires the astronauts to fix a broken or non-functional piece of equipment which involves troubleshooting and testing in order to deal with an unforeseen situations [9].

Housekeeping: since ISS is a lonely and expensive place, astronauts have to maintain their regular hygiene and hygienic environment. The microgravity add complexity if the surrounding is messy as tiny debris or dust of any kind can float around and become lodged in the circuits and cause damage or even astronauts could inhale them.

Therefore it's even more important in space comply with the following activities:

- Cleaning the bathroom and kitchen areas using a vacuum cleaner to clean the control panels and air vents and to remove all undesirable matter from the ambient air;

- Disinfecting experimental or other equipment to eliminate any potentially harmful bacteria [9].

\section{ACKNOWLEDGMENT}

a particular acknowledgment is addressed to engineering students, Basnet Suman and Shrivastava Rakshita Raj, for their contribution in the development of the present research.

\section{REFERENCES}

[1] NASA ISS Research Program. 2009.

[2] NASA Current ISS Tracking data. 2009.

[3] Reference guide to International Space Station.

ISBN 978-0-16-086517-6. 2010.

[4] NASA ISS On Orbit Status. 2010.

[5] Pete Harding. ISS: Dextre and RRM complete second round of joint ops. CDRA recovered. 2012.

[6] NASA. International Space Station Status. 2018.

[7] Gerald Griffith, Texas and Tateo Goka, Ph.D. "The Space Environment: Natural and Induced".

Safety design for space systems. G. Musgrave, A. Larsen, T. Sgobba. 2009.

[8] Orbital Debris Quarterly News, Volume 22, Issue 1. 2018.

[9] C.A. Belk, W.J. Cooke, S.D. Pavelitz, J.H. Robinson and M.B. Alexander.

Meteoroids and Orbital Debris: Effects on Spacecraft. 1997.

[10] J.R. Goodman, F. Grosveld. "Noise Control Design".

Safety Design for Space Systems. G. Musgrave, A. Larsen, T. Sgobba. 2009.

[11] W. Hammar. Product Safety Management and Engineering.

Des Plaines. American Society of Safety Engineers Press. 1993.

[12] T. Sgobba, A.M. Larsen, G.E. Musgrave. "Basic Principles of Space Safety".

Safety Design for Space Systems. 2009.

[13] Final Report of the International Space Station Independent Safety Task Force. 2007.

[14] E. L. Christiansen, K. Nagy, D. M. Lear, T. G. Prior. "Space Station MMOD Shielding".

Acta Astronautica. Volume 65, Issues 7-8. Elsevier. 2009.

[15] G. A. Ruff, D. L. Urban, M. D. Pedley, P. T. Johnson. "Fire Safety".

Safety Design for Space Systems. G. Musgrave, A. Larsen, T. Sgobba. 2009. 